\section{RECIS}

ISSN: $2675-9683$

\section{Revista de Ensino, Ciência e Inovação em Saúde}

Homepage:http://recis.huunivasf.ebserh.gov.br

\title{
Avaliação da população bacteriana em superfícies e equipamentos da sala de emergência do Hospital Universitário da Universidade Federal do Vale do São Francisco
}

\section{Evaluation of the bacterial population on surfaces and equipments at the emergency room of the University Hospital of the Federal University of Vale do São Francisco}

\begin{abstract}
Ricardo Leal da Silva ${ }^{1}$ Katia Suely Batista Silva ${ }^{2}$ Sued Sheila Sarmento ${ }^{3}$ Gabriella Tavares Pinto de Luna $^{4}$ Katia Regina de Oliveira ${ }^{5}$ Marcos Duarte Guimarães ${ }^{6}$ Carine Rosa Naue ${ }^{7}$

${ }^{1}$ Enfermeiro residente em Urgência e Emergência Hospital Universitário da Universidade do Vale do São Francisco, ${ }^{2}$ Técnica em Enfermagem do Hospital Universitário da Universidade Federal do Vale do São Francisco/EBSERH, ${ }^{3}$ Docente do Curso de Enfermagem da Universidade Federal do Vale do São Francisco, ${ }^{4}$ Discente do Curso de Medicina da Universidade Federal do Vale do São Francisco, ${ }^{5}$ Médica Intensivista da Hospital Universitário da UNIVASF, ${ }^{6}$ Docente do Curso de Medicina da UNIVASF, ${ }^{7}$ Bióloga do Hospital Universitário da Universidade Federal do Vale do São Francisco/EBSERH
\end{abstract}

Autor para correspondência: carine.naue@ebserh.gov.br Artigo recebido em 10/10/2021 e aceito em 07/12/2021

\begin{abstract}
RESUMO
As infecções hospitalares (IH), atualmente denominadas IRAS, elevam consideravelmente os custos no cuidado do paciente, além de aumentar o tempo de internação, morbidade e mortalidade nos serviços de saúde. O objetivo deste trabalho foi avaliar o perfil bacteriano das superfícies e equipamentos da Sala de Emergência de um hospital universitário. Trata-se de um estudo exploratório com abordagem quantitativa, o qual foi realizado na Sala de Emergência do Hospital Universitário da Universidade Federal do Vale do São Francisco (HU-UNIVASF/EBSERH). A coleta foi realizada em cinco leitos onde foram analisados o ventilador mecânico, os botões de comando do monitor cardíaco, a mesa da cabeceira, o diafragma do estetoscópio, a haste metálica do soro e a parede ao redor de cada leito. Os swabs foram passados nas superfícies e equipamentos e armazenados em tubos com $5 \mathrm{ml}$ meio líquido BHI (Brain Heart Infusion). Para isolamento dos microrganismos, as amostras foram semeadas em Ágar Sangue (AS) e incubadas a $37^{\circ}$ por 24 horas. Após a incubação foi realizada a coloração de Gram, provas bioquímicas e o antibiograma. Os dados foram digitados em arquivos no formato de planilhas e gráficos e realizada análise descritiva. Obteve-se um total de trinta amostras dos cinco leitos resultando em um total de quarenta e três isolados bacterianos, entre elas, Staphylococcus coagulases negativa, bacilos gram positivo e duas possíveis espécies bacterianas causadores de infecções relacionadas à assistência à saúde, Escherichia vulneralis e Pseudomonas pseudoalcaligenes. Foram isoladas apenas duas espécies possíveis causadoras de infecções que se apresentaram sensíveis a todos os antibióticos testados.

Palavras-chave: Infecção hospitalar; Bactérias; Emergência.
\end{abstract}

\section{ABSTRACT}

Hospital infections (HI), currently called HAI, considerably increase the costs of patient care, in addition to increasing the length of stay, morbidity and mortality in health services. The objective of this work was to evaluate the bacterial

Silva, R. L. et al. / Revista de Ensino, Ciência e Inovação em Saúde v. 2 n. 3 (2021) p. 68-74 
profile of surfaces and equipments at the Emergency Room of a university hospital. This is an exploratory study with a quantitative approach, which was carried out in the Emergency Room of the University Hospital of the Federal University of Vale do São Francisco (HU-UNIVASF/EBSERH). The collection was carried out in five beds where the mechanical ventilator, the cardiac monitor control buttons, the bedside table, the stethoscope diaphragm, the metallic serum rod and the wall around each bed were analyzed. Swabs were passed over surfaces and equipments and stored in tubes with $5 \mathrm{ml}$ BHI liquid medium (Brain Heart Infusion). For isolation of microorganisms, samples were seeded in Blood Agar (BA) and incubated at $37^{\circ}$ for 24 hours. After incubation, Gram stain, biochemical tests and antibiogram were performed. Data were entered into files in the form of spreadsheets and graphics and descriptive analysis was performed. A total of thirty samples were obtained from the five beds resulting in a total of forty-three bacterial isolates, including coagulase negative Staphylococcus, gram positive bacilli and two possible bacterial species causing infections related to healthcare, Escherichia vulneralis and Pseudomonas pseudoalcaligenes. Only two possible infection-causing species that were sensitive to all tested antibiotics were isolated.

Keywords: Hospital infection; Bacteria; Emergency.

\section{INTRODUÇÃO}

As Infecções relacionadas a assistência à saúde (IRAS), ocorrem durante o processo de atendimento em um hospital ou em outro estabelecimento de saúde, após 72h da admissão ou alta do paciente, desde que estejam relacionadas com sua internação ou procedimentos hospitalares. ${ }^{1}$ As IRAS representam o evento adverso mais frequente durante a prestação de cuidados, podendo-se estimar que a cada ano, milhões de pacientes em todo o mundo são afetados por estas, sendo o ônus maior nos países menos desenvolvidos. $^{2}$

As infecções hospitalares (IH), atualmente denominadas IRAS, elevam consideravelmente os custos no cuidado do paciente, além de aumentar o tempo de internação, a morbidade e a mortalidade nos serviços de saúde. ${ }^{3}$ A alta frequência destas infecções está associada ao uso de dispositivos invasivos, em particular, linhas centrais, cateteres urinários e ventiladores. ${ }^{2}$

As principais IRAS são as pneumonias associadas à ventilação, as do trato urinário, as da corrente sanguínea e as do sítio cirúrgico, sendo o profissional o principal responsável pela busca em sua redução, através de medidas preventivas e práticas adequadas à realidade brasileira. ${ }^{3}$

Umas das causas das IRAS é a contaminação cruzada, ocasionada pela transmissão de microrganismos entre pacientes, mãos de profissionais, acompanhantes e visitantes. ${ }^{4-5}$ Pesquisas mostram que o ambiente hospitalar, também possui um importante papel nas infecções cruzadas. Os ambientes ocupados rotineiramente por pacientes infectados ou colonizados apresentam-se mais propícios para a disseminação destas infecções; muitas superfícies inanimadas que cercam o paciente nestes ambientes abrigam microrganismos patogênicos, os quais guardam estreita relação com as infecções hospitalares, podendo assim vir a ser foco de contato e transmissão para os pacientes. ${ }^{4-5}$
As bactérias multirresistentes são encontradas em superfícies e equipamentos médicos e são capazes de sobreviver até meses em superfícies secas inanimadas, com persistência mais longa sob baixas e úmidas temperaturas. ${ }^{6}$

Além do papel do ambiente hospitalar nas infecções cruzadas, já está consolidado na literatura científica, que a correta higienização das mãos é uma importante medida de prevenção e controle destas infecções, uma vez que, as mãos dos profissionais de saúde continuam sendo a principal e mais frequente fonte de contaminação e disseminação de microrganismos. ${ }^{7}$

A política Nacional de Urgência e Emergência define o setor de emergência como uma porta de entrada do SUS, devendo atender todo e qualquer paciente, priorizando as linhas de atendimento cardiovascular, cerebrovascular e traumatologia. ${ }^{8}$ No entanto, existe uma alta demanda principalmente na linha de traumas, o que interfere na sobrecarga de profissionais, dificulta a higienização de superfícies e equipamentos e consequentemente aumenta o risco das IRAS. ${ }^{9}$

Diante do crescimento das IRAS dentro do ambiente hospitalar e a importância das superfícies na contaminação cruzada, pesquisas que avaliem a microbiota da Instituição são relevantes, pois irão mostrar o perfil bacteriano em superfícies e equipamentos, proporcionando o conhecimento da microbiota que fornecerá dados a fim de estabelecer medidas preventivas e reduzir o índice de infecção dentro do hospital. Diante deste exposto, o objetivo deste trabalho foi avaliar o perfil bacteriano das superfícies e equipamentos na Sala de Emergência do Hospital Universitário da Universidade Federal do Vale do São Francisco.

\section{MATERIAL E MÉTODOS}

Trata-se de um estudo do tipo descritivoexploratório com abordagem quantitativa, realizado na Sala de Emergência do Hospital 
Revista de Ensino, Ciência e Inovação em Saúde v.2, n.3 (2021) 68-74

ISSN: 2675-9683/ DOI: 10.51909/recis.v2i3.195

Universitário da Universidade Federal do Vale do São Francisco (HU-UNIVASF/EBSERH), no interior de Pernambuco, que tem referência em trauma, politrauma, ortopedia, neurocirurgia, clínica geral e médica, com perfil de média e alta complexidade e dimensionamento de serviços assistenciais e de ensino e pesquisa.

A coleta ocorreu no período de Junho a Setembro de 2020. As amostras foram coletadas em cinco (05) leitos sendo duas amostras para cada item. Foram analisados: 1- Ventilador Mecânico (VM) com a coleta no botão liga/desliga e no botão multifunção, 2- monitor cardíaco (MC) no botão liga/desliga e no botão multifunção, 3- colchão de macas $(\mathrm{CM})$ sendo a $1^{\mathrm{a}}$ amostra na parte inferior e a $2^{\mathrm{a}}$ na lateral do colchão, 4- paredes ao redor do leito (PR) com a $1^{\mathrm{a}}$ amostra na parte inferior e a $2^{\mathrm{a}}$ na parte superior, 5- suporte de soro (SP) na parte superior e inferior e 6- grades das macas (GD) $1^{\mathrm{a}}$ amostra lateral direita e $2^{\mathrm{a}}$ parte lateral esquerda. Para as coletas das amostras das superfícies e dos equipamentos foi utilizado um molde de papel filtro de área de $1 \mathrm{~cm}^{2} \mathrm{e}$ swabs embebidos em solução salina. Os swabs foram passados nas superfícies e equipamentos e armazenados em tubos com $5 \mathrm{ml}$ meio líquido BHI (Brain Heart Infusion). Em seguida as amostras foram transportadas para o Laboratório de Análises Clínicas do Hospital onde foram incubados a $37^{\circ}$ por 24 horas. Para isolamento dos microrganismos, as amostras foram semeadas em Ágar Sangue (AS) e incubadas a $37^{\circ}$ por 24 horas. Após a incubação foi realizada a coloração de Gram e provas bioquímicas para identificação de cada espécie. $\mathrm{Na}$ identificação de cocos gram-positivos foi utilizada a prova de catalase. Quando positiva foi realizada a prova de coagulase e quando negativa foi utilizado o kit para Enterococcus, bacitracina e optoquina identificando as espécies. Na identificação de bacilos gram negativos foram utilizados kits para identificação de enterobactérias e/ou de não fermentadores da PROBAC®. As bactérias identificadas foram submetidas ao antibiograma pelo método de Ágar Difusão em disco conforme as instruções CLSI (2020) e a escolha do antimicrobiano foi de acordo com o microrganismo isolado. Os dados foram digitados em arquivos no formato de planilhas e gráficos nos softwares Excel e Word da Microsoft Office versão 7.0 Windows e realizada análise descritiva com valores absolutos e em percentuais.

\section{RESULTADOS}

Obteve-se um total de trinta (30) amostras dos cinco leitos resultando em um total de quarenta e três isolados bacterianos sendo que, dessas, duas espécies bacterianas foram mais frequentes a Staphylococcus coagulases negativa, presente vinte oito vezes nas amostras e bacilos gram-positivo, treze vezes, e dois possíveis gêneros bacterianos causadores de infecções relacionadas à assistência à saúde: Escherichia vulneralis e Pseudomonas pseudoalcaligenes. Não houve crescimento bacteriano nos seguintes equipamentos: grades do leito um e cinco, parede do leito dois, quatro e cinco, monitor cardíaco do leito dois, três, quatro e cinco conforme mostra a (Tabela 1).

Em se tratando do perfil de resistência e sensibilidade aos antibióticos testados, não ocorreu resistência para os isolados da Pseudomonas pseudoalcaligenes e Escherichia vulneralis, sendo quee a sensibilidade foi de $100 \%$ aos seguintes antibióticos: amicacina, ampicilina, ampicilinasulbactam, cefazolina, cefepima, cefoxitina, ceftriaxona, ciprofloxacina, ertapenem, gentamicina, imipenem, meropenem, piperacilinatazobactam, tigeciclina e trimetoprimsulfametoxazol.

\section{DISCUSSÃO}

O presente trabalho mostrou uma microbiota que é bem comum no ambiente hospitalar assim como outras pesquisas na mesma linha também mostraram microbiota semelhante. Mendes e Brasileiro $^{10}$ realizaram isolamento bacteriano de superfícies em uma Unidade de Terapia Intensiva como mesa de cabeceira, teclado de computador, bancada para preparo de medicamentos, escala de enfermagem e monitor e a principal bactéria encontrada pelos pesquisadores foi Staphylococcus coagulase negativa (SCN) a qual também foi encontrada no presente estudo. ${ }^{10}$

Os Staphylococcus coagulase negativa são assim classificados por não apresentarem a enzima coagulase que colonizam a pele e mucosas, têm ainda a capacidade de formar biofilmes dificultando a penetração e ação dos antibióticos ${ }^{11}$ e são patógenos potencialmente causadores de IRAS associados à infecção de corrente sanguínea, infecção de sítio cirúrgico e bacteremias. ${ }^{10}$ 
Revista de Ensino, Ciência e Inovação em Saúde v.2, n.3 (2021) 68-74

ISSN: 2675-9683/ DOI: $\underline{10.51909 / \text { recis.v2i3.195 }}$

Tabela 1. Amostras de equipamentos e superfícies que apresentaram ou não crescimento bacteriano na Sala de Emergência do Hospital Universitário da Universidade Federal do Vale do Vale do São Francisco

*Sem crescimento(SC) *Staphylococcus coagulases negativa $(\mathrm{SCN}) *$ Bacilo-gram positivo (BGP)

\begin{tabular}{|c|c|c|c|c|c|}
\hline Equipamentos & Leito 01 & Leito 02 & Leito 03 & Leito 04 & Leito 05 \\
\hline Ventilador & SC & SCN & SC & BGP & $\mathrm{SC}$ \\
\hline Mecânico & $\mathrm{SCN}$ & BGP & $\mathrm{SCN}$ & $\mathrm{SCN}$ & $\mathrm{SCN}$ \\
\hline \multirow[t]{2}{*}{ Suporte de Soro } & $\mathrm{SC}$ & SCN & $\mathrm{SC}$ & $\mathrm{SC}$ & $\mathrm{SCN}$ \\
\hline & BGP & SC & $\mathrm{SCN}$ & & \\
\hline Grades & SC & $\mathrm{SCN}$ & BGP & Escherichia & $\mathrm{SC}$ \\
\hline macas & & & $\mathrm{SCN}$ & vulneralis & \\
\hline & & & & $\mathrm{SCN}$ & \\
\hline Paredes ao redor & $\mathrm{SCN}$ & $\mathrm{SC}$ & BGP & $\mathrm{SC}$ & $\mathrm{SC}$ \\
\hline dos leitos & $\begin{array}{l}\text { Pseudomonas } \\
\text { pseudoalcaligenes }\end{array}$ & & & BGP & $\mathrm{SCN}$ \\
\hline Monitor & SCN & $\mathrm{SC}$ & $\mathrm{SC}$ & $\mathrm{SC}$ & $\mathrm{SC}$ \\
\hline Cardíaco & & SCN & & & \\
\hline Colchão & $\mathrm{SCN}$ & $\mathrm{SC}$ & $\mathrm{SCN}$ & $\mathrm{SCN}$ & $\mathrm{SCN}$ \\
\hline macas & BGP & BGP & & & BGP \\
\hline
\end{tabular}

IRAS associados à infecção de corrente sanguínea, infecção de sítio cirúrgico e bacteremias. $^{10}$

Em estudo realizado por Souza et al (2019). ${ }^{5}$ seguindo a mesma linha de pesquisa analisaram mesas de cabeceira, grades de macas e bombas de infusão totalizando quarenta e quatro (44) superfícies contaminadas. A maior incidência de contaminação foi nas grades de macas nove (09), cama cinco (05) e mesa de cabeceira quatro (04) e mesmo depois da realização de desinfecção foram encontrados dezoito (18) microrganismos nessas superfícies.

Nota-se que a incidência de bactérias no estudo foi reduzida em comparação a estudos na mesma linha de pesquisa e isso pode estar atrelado ao momento de pandemia, visto que os profissionais estão a todo tempo buscando mais medidas preventivas e a higienização das superfícies e equipamentos se tornou mais rigorosa, os cuidados dos pacientes também estão redobrados, ou seja, interferindo

diretamente reduzindo as taxas de IRAS no ambiente hospitalar.

Outra bactéria encontrada no estudo foi a Escherichia vulneralis, que é um bacilo gram negativo, anaeróbio facultativo que não forma esporos e seu crescimento ocorre idealmente entre $35^{\circ}$ e $37^{\circ} \mathrm{C}$, são bacilos móveis e seu habitat é ambiental, encontrada principalmente na água e no solo, porém é um patógeno oportunista se comportando como colonizador em humanos e animais. ${ }^{13}$ Em relação a suscetibilidade antibacteriana descreve boa sensibilidade a cefalosporinas e aminoglicosídeos. ${ }^{13}$ Este patógenos é um patógeno humano sendo observadas em infecções invasivas em pacientes adultos e indivíduos imunossuprimidos. ${ }^{14}$

No presente estudo a presença da Escherichia vulneralis foi vista nas grades das macas o que é notório devido o número elevado de manipulação por profissionais quando realizam procedimentos.

Também presente no estudo a Pseudomonas pseudoalcaligenes é uma espécie do gênero Pseudomonas que são bacilos gram 
negativos aeróbios, não fermentadores, móveis e geralmente encontrados aos pares, vivem em ambientes variados, principalmente no solo, matéria orgânica em decomposição sendo também encontrada no ambiente hospitalar. ${ }^{15}$

É considerada um patógeno oportunista, haja vista que em condições normais o organismo consegue combatê-la, são responsáveis por um importante problema de saúde pública, pela sua morbidade, frequência, mortalidade e custo de tratamento. São reconhecidas pela alta resistência a todas as classes de antibióticos e capacidade de desenvolver novos mecanismos de defesa, principalmente por mutação. ${ }^{15}$ É um agente patogênico que pode causar doenças como: infecções do trato urinário, infecções do trato respiratório, infecções da pele e tecidos moles, esta bactéria permanece como um dos mais prevalentes agentes das IRAS pela habilidade que possui de se desenvolver no próprio ambiente hospitalar, como no ar, em reservatórios de água e outros fluidos e em superfícies inanimadas que cercam o paciente, proporcionando focos de contato e transmissão. ${ }^{16}$

Notou-se no estudo a presença do gênero Pseudomonas, principalmente nas paredes ao redor do leito o que evidencia a capacidade de contaminação devido ser tocada inúmeras vezes tanto pelos profissionais quanto por pacientes e acompanhantes. Esta bactéria é responsável por aproximadamente quinze por cento $(15 \%)$ de bacteremia por germes gram negativos, a mortalidade nesses casos chega a ser de cinquenta por cento (50\%), o diagnóstico da infecção é feita pela cultura do material proveniente do processo infeccioso. ${ }^{16}$

Em um estudo realizado por Gil et al (2018). ${ }^{17}$ dentro de uma unidade de terapia intensiva nas bombas de infusão e grades de leitos foi detectada também alta incidência de bactérias, chamando atenção as grades com a presença de $S$. haemolyctus e $S$. hominis 33,3\%, seguido por $S$. simulans $22,2 \%$ e nas bombas $S$. haemolyctus $62,5 \%$ S. hominis $37,5 \%$ sendo que desses os microrganismos $S$. hominis, $S$. haemolyctus se apresentaram como multirresistentes.

Observa-se que no presente estudo quanto ao perfil de resistência e sensibilidade não foi detectado resistência aos antibióticos que foram testados, o que difere dos resultados observados de superfícies e equipamentos de uma UTI, onde foram isoladas bactérias patogênicas com um elevado grau de resistência aos antibióticos. ${ }^{18-19}$.

\section{CONCLUSÃO}

Foram isoladas as espécies bacterianas como Pseudomonas pseudoalcaligenes e Escherichia vulneralis, gram negativas causadoras de IRAS que estiveram presentes nos equipamentos da emergência que podem elevar o nível de possíveis infecções cruzadas. Portanto é relevante o cuidado de todos os profissionais que estão no setor a fim de minimizar o risco de infecção, assim como manter uma comunicação com a equipe multidisciplinar, visando orientá-la quanto aos cuidados de higienização das mãos, realização de técnicas assépticas e uso racional de antibióticos pela equipe médica.

É relevante ressaltar que a incidência de bactérias nos equipamentos e superfícies em comparação com outros estudos não foi alta e isso se observa devido o cenário de pandemia e os cuidados que estão sendo adotados por profissionais de saúde e todos que fazem parte do ambiente hospitalar inclusive os pacientes.

\section{REFERÊNCIAS}

1. BRASIL. Ministério da Saúde. Portaria $n^{\circ}$ 2616, de 12 de maio de 1998. Diretrizes e normas para prevenção e o controle das infecções hospitalares. Diário Oficial da União. Brasília (DF), 1998 mai 13. Disponível em: https://bvsms.saude.gov.br/bvs/saudelegis/gm/ 1998/prt2616 $12 \quad 05 \quad$ 1998.html.

2. WHO, World Health Organization. Prevenção e Controle de infecções. O ônus da Infecção associada à Assistência Médica em todo o mundo. [Internet]. 2021 [citado 2021 mai 20]. Disponível em: https://www.who.int/infectionprevention/publications/burden_hcai/en/

3. Agência Nacional de Vigilância Sanitária (ANVISA). Medidas de Prevenção de Infecção Relacionada à Assistência à Saúde. Brasília: ANVISA, 2017.Disponível em: https://www.gov.br/anvisa/ptbr/centraisdeconteudo/publicacoes/servicosdes aude/publicacoes/caderno-4-medidas-deprevencao-de-infeccao-relacionada-aassistencia-a-saude.pdf/view 
ISSN: 2675-9683/ DOI: 10.51909/recis.v2i3.195

4. Lima LKOL, Pinto JCG, Misael LS, et al. Avaliação da contaminação cruzada por Acinetobacter spp. em uma unidade de terapia intensiva. Revista de Epidemiologia e Controle de Infecção 2019; 9(3). https://doi.org/10.17058/reci.v9i3.12510

5. Souza ME, Ferreira H, Zilly A, et al. Condições de desinfecção de superfícies inanimadas em unidades de terapia intensiva. Revista de Pesquisa Cuidado é Fundamental Online 2019; 11(4): 951-956. http://dx.doi.org/10.9789/21755361.2019.v11i4.951-956

6. Russotto V, Cortegiani A, Raineri SM, et al. Bacterial contamination of inanimate surfaces and equipment in the intensive care unit. Journal of Intensive Care 2015; 3(1):54. https://doi.org/10.1186/s40560-015-0120-5

7. Jezewski GM, Loro MM, Herr GEG, et al. Knowledge on hand hygiene by nursing professionals from a private hospital. Revista Cuidarte 2017;8(3): 1777-1785. https://doi.org/10.15649/cuidarte.v8i3.419

8. BRASIL. Ministério da Saúde. Portaria $n^{\circ}$ 1.600, de 7 de julho de 2011. Reformula a Política Nacional de Atenção às Urgências e institui a Rede de Atenção às Urgências no Sistema Único de Saúde. Diário Oficial da União. Brasília (DF), 2011 jul 8. Disponível em:

https://bvsms.saude.gov.br/bvs/saudelegis/gm/ $\underline{\text { 2011/prt1600 } 07 \quad 07 \quad 2011 . h t m l}$

9. Silva JKC, Matos E, Eliane, Souza SS. Bundle de cuidados para a prevenção e o controle de infecção hospitalar em serviço de emergência adulto. Revista de Pesquisa: Cuidado é Fundamental 2020; 12: 176-182. http://dx.doi.org/10.9789/2175-

5361.rpcfo.v12.7192.

10. Mendes JR, Brasileiro MSE. Proposta de protocolo para descontaminação de equipamentos em unidade de terapia intensiva. Revista de Enfermagem do CentroOeste Mineiro 2017;7. https://doi.org/10.19175/recom.v7i0.2346

11. Dong Y, Speer CP. The role of Staphylococcus epidermidis in neonatal sepsis: guarding angel or pathogenic devil?. International Journal of Medical Microbiology 2014; 304 (5-6):513-520. https://doi.org/10.1016/j.ijmm.2014.04.013

12. Acquaviva R, D'Angeli F, Malfa GA, et al. Antibacterial and anti-biofilm activities of walnut pellicle extract (Juglans regia L.) against coagulase-negative staphylococci. Natural Product Research 2019; 35(12):1-6.

https://doi.org/10.1080/14786419.2019.165035 $\underline{2}$

13. Pérez $\mathrm{C}$, Melo $\mathrm{P}$, Besomi $\mathrm{J}$, et al. Escherichia vulneris como agente etiológico de artritis séptica en una niña. Revista chilena de infectologia 2018; 35(1):80-82. http://dx.doi.org/10.4067/s071610182018000100080

14. Jain $S$, Nagarjuna $D$, Gaind $R$, et al. Escherichia vulneris: an unusual cause of complicated diarrhoea and sepsis in an infant. A case report and review of literature. New microbes and new infections, 2016;13: 83-86. https://doi.org/10.1016/j.nmni.2016.07.002

15. Revista Analytica [homepage na internet]. Microbiologia: pseudomonas/analytica 94. [acesso em 01 mai 2021]. Disponível em: https://revistaanalytica.com.br/microbiologiapseudomonas-analytica-94/

16. Ciências News [homepage na internet]. Infecções por Pseudomonas aerugionosa. [acesso 01 mai 2021]. Disponível em: https://www.ciencianews.com.br/arquivos/AC ET/IMAGENS/revista_virtual/microbiologia/ micro07.pdf.

17. Gil AC, Bordignon APP, Castro EAR, et al.Avaliação microbiológica de superfícies em terapia intensiva: reflexões sobre as estratégias preventivas de infecções nosocomiais. Revista Enfermagem Uerj 2018; 26. https://doi.org/10.12957/reuerj.2018.26388

18 Espíndola MCM, Andrade CWQ, Silva $\mathrm{KSB}$, et al. Perfil bacteriano das superfícies e equipamentos da Unidade de Terapia Intensiva de um Hospital Universitário. Research, Society and Development 2021;10(9), e47510918342. http://dx.doi.org/10.33448/rsd-v10i9.18342 
Revista de Ensino, Ciência e Inovação em Saúde v.2, n.3 (2021) 68-74

ISSN: 2675-9683/ DOI: 10.51909/recis.v2i3.195

19 Santos AB, Batista Silva KS, Santana MMR, et al. Perfil bacteriano das superfícies e equipamentos do Bloco Cirúrgico de um
Hospital Universitário. Vittalle - Revista de Ciências da Saúde 2020; 32(1): 101-107. https://doi.org/10.14295/vittalle.v32i1.11048 